\title{
Composição do meio de cultura e condições ambientais para germinação de grãos de pólen de porta-enxertos de pereira
}

\author{
Medium composition and environmental conditions for the germination of pollen grains \\ of pear rootsocks
}

\author{
Edvan Alves Chagas ${ }^{\mathrm{I}}$ Rafael Pio ${ }^{\mathrm{II}}$ Pollyana Cardoso Chagas $^{\mathrm{III}}$ Moacir Pasqual ${ }^{\mathrm{II}}$ \\ José Emílio Bettiol Neto ${ }^{\mathrm{IV}}$
}

\section{RESUMO}

Visando a dar suporte a trabalhos de melhoramento genético para porta-enxertos de pera e ajuste de protocolo de germinação de pólen para fins de polinização intra e interespécies, objetivou-se ajustar os componentes básicos do meio de cultura e as condições ambientais para a realização de testes de germinação in vitro $e$ viabilidade de grãos de pólen dos porta-enxertos para pereiras 'Taiwan NashiC' (Pyrus calleryana) e 'Taiwan Mamenashi' (P. betulaefolia). $O$ pólen utilizado foi obtido de anteras provenientes de flores em estádio de balão. Em seguida, com auxílio de um pincel $n$-2, os grãos de pólen foram espalhados sobre a superfície de placas de Petri, contendo $20 \mathrm{ml}$ de meio de cultura de acordo com os seguintes experimentos: 1) concentrações de sacarose (0, 30, 60 e $\left.90 \mathrm{~g} \mathrm{~L}^{-1}\right)$ e agar (4, 6, 8 e $\left.10 \mathrm{~g} \mathrm{~L}^{-1}\right)$; 2) concentrações de nitrato de cálcio $\left(0,200,400\right.$ e $\left.800 \mathrm{mg} \mathrm{L}^{-1}\right)$ e ácido bórico $\left(0,400,800\right.$ e $\left.1200 \mathrm{mg} \mathrm{L}^{-1}\right)$; 3) valores de $\mathrm{pH}(4,0 ; 4,5 ; 5,0$; 5,5; 6,0 e 6,5); 4) temperaturas (20; 25; 30 e 35); e 5) tempo de emissão do tubo polínico (1, 2, 3, 4, 5, 6 e 12 horas após a inoculação), os quais foram montados de forma sequencial. A utilização de $10 \mathrm{~g} \mathrm{~L}^{-1}$ de agar e $90 \mathrm{~g} \mathrm{~L}^{-1}$ de sacarose para o porta-enxerto 'Taiwan Mamenashi' e 47,78g L-1 para 'Taiwan Nashi-C', com 795 a 838mg $L^{-1}$ de ácido bórico, na ausência de nitrato de cálcio, $\mathrm{pH}$ entre 5,2 e 5,8 e temperatura de $28^{\circ} \mathrm{C}$, proporcionou as melhores condições de germinação de grãos de grãos. A porcentagem máxima de polens germinados é obtida com oito horas após a inoculação para 'Taiwan NashiC' e com 12 horas para 'Taiwan Mamenashi'.

Palavras-chave: sacarose, agar, nitrato de cálcio, ácido bórico, $\mathrm{pH}$, temperatura.

\begin{abstract}
In order to support the works with genetic improvement for pear rootstocks and adjust the pollen germination protocol for intra and inter species polinization, this study aimed to adjust the culture medium basic compounds and environmental conditions for the realization of in vitro pears pollen grains germination and viability tests of 'Taiwan Nashi-C' (Pyrus calleryana) e 'Taiwan Mamenashi' (P. betulaefolia) pear rootstock. Thus, five experiments were performed: 1) Sucrose concentrations (0, 30, 60 and $\left.90 \mathrm{~g} \mathrm{~L}^{-1}\right)$ and agar (4, 6, 8 and $\left.10 \mathrm{~g} \mathrm{~L}^{-1}\right)$; 2) calcium nitrate (0, 200, 400 and $\left.800 \mathrm{mg} \mathrm{L}^{-1}\right)$ and boric acid $\left(0,400,800\right.$ and $\left.1200 \mathrm{mg} \mathrm{L}^{-1}\right)$; 3) $\mathrm{pH}(4.0 ; 4.5 ; 5.0 ; 5.5 ; 6.0$ and 6.5$)$; 4) temperatures $(20$; 25; 30 and 35 ) and 5) emission time of the pollen tube (1, 2, 3, 4, 5, 6 and 12 hours after inoculation), which were assembled sequentially. The use of $10 \mathrm{~g} \mathrm{~L}^{-1}$ of agar combined with $90 \mathrm{~g} \mathrm{~L}^{-1}$ sucrose for the rootstock 'Taiwan Mamenashi' and $47.78 \mathrm{~g} \mathrm{L^{-1 }}$ for the 'Taiwan Nashi-C', with 795 to $838 \mathrm{mg} \mathrm{L}^{-1}$ of boric acid, under absence of calcium nitrate and $\mathrm{pH}$ between 5.2 and 5.8 and temperature of $28{ }^{\circ} \mathrm{C}$, provided the best conditions to the germination of the pollen grains. The maximum percentage of germinated pollen is obtained with eight hours after inoculation for 'Taiwan Nashi-C' and twelve hours for 'Taiwan Mamenashi'.
\end{abstract}

Key words: sucrose, agar, calcium nitrate, boric acid, $p H$, temperature.

\section{INTRODUÇÃO}

Trabalhos de melhoramento genético do Instituto Agronômico (IAC) originários de espécies e cultivares adaptadas ao clima subtropical possibilitam

\footnotetext{
IEmpresa Brasileira de Pesquisa Agropecuária (EMBRAPA-CPAFRR), Boa Vista, RR, Brasil.

IUniversidade Federal de Lavras (UFLA), CP 3037, 37200-000, Lavras, MG, Brasil. E-mail: rafaelpio@hotmail.com.*Autor para correspondência.

IIIEscola Superior de Agricultura Luiz de Queiroz (ESALQ), Universidade de São Paulo (USP), Piracicaba, SP, Brasil.

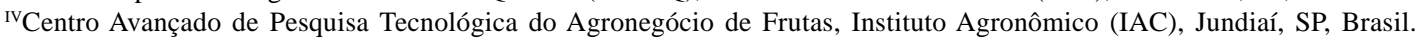


a expansão do cultivo de pera em regiões de inverno ameno. No entanto, verifica-se carência de portaenxertos adaptados às condições climáticas brasileiras, ficando dependentes somente de dois porta-enxertos 'Taiwan Nashi-C' (Pyrus calleryana) e 'Taiwan Mamenashi' (P. betulaefolia) (BARBOSA et al., 1998; 2007).

A técnica mais utilizada na obtenção de novas cultivares é a hibridação controlada no campo e posterior avaliação das progênies. A análise da fertilidade dos grãos de pólen dos progenitores coletado a campo ou armazenado sob condições adequadas é condição preliminar indispensável antes de iniciar os cruzamentos, uma vez que o período anual de floração das pereira é curto e, caso os polens não estejam viáveis, pode inviabilizar os cruzamentos.

Existe uma relação entre a porcentagem de germinação e viabilidade do pólen (BOLAT \& PIRLAK, 1999). Sabe-se que vários compostos orgânicos e inorgânicos interferem na germinação in vitro, dos quais o agar, a sacarose, o cálcio e o boro são os mais importantes. Contudo, existem outros fatores, como o pH do meio de cultura e a temperatura de germinação, que influenciam significativamente a germinação e viabilidade dos grãos de pólen (GALLETA, 1983).

Nesse sentido, informações sobre viabilidade e desenvolvimento de grãos de pólen desses porta-enxertos de pereira são fundamentais para trabalhos de biologia reprodutiva e melhoramento genético, pois permitem obter maior sucesso nos cruzamentos controlados que tem como objetivo gerar novos híbridos e/ou aumentar a variabilidade genética.

Assim, objetivou-se, com o presente trabalho, ajustar os componentes básicos do meio de cultura e as condições ambientais para a realização de testes de germinação in vitro e viabilidade de grãos de pólen dos porta-enxertos de pereira 'Taiwan Nashi-C' e 'Taiwan Mamenashi'.

\section{MATERIAL E MÉTODOS}

Os grãos de pólen foram obtidos de anteras provenientes de flores em estádio de balão, no mês de agosto, em plantas matrizes de nove anos de idade, enxertadas sobre o porta-enxerto 'Taiwan Nashi-C'. Após a separação das anteras, estas foram acondicionadas em placas de Petri forradas com papel de filtro e colocadas em sala de secagem sob temperatura de $25^{\circ} \mathrm{C}$, durante 12 horas, para a completa deiscência e liberação do polínio.

Em seguida, com auxílio de um pincel no , os grãos de pólen foram espalhados sobre a superfície das placas de Petri contendo $20 \mathrm{ml}$ de meio de cultura de acordo com os seguintes experimentos: 1$)$ concentrações de sacarose $\left(0,30,60\right.$ e $\left.90 \mathrm{~g} \mathrm{~L}^{-1}\right) \mathrm{x}$ agar $\left(4,6,8\right.$ e $\left.10 \mathrm{~g} \mathrm{~L}^{-1}\right)$ x porta-enxertos com aferição de $\mathrm{pH}$ para 5,8 e na ausência de ácido bórico e nitrato de cálcio; 2) concentrações de nitrato de cálcio $(0,200$, 400 e $\left.800 \mathrm{mg} \mathrm{L}^{-1}\right)$ x ácido bórico (0, 400, 800 e 1200 $\left.\mathrm{mg} \mathrm{L}^{-1}\right)$ $\mathrm{x}$ porta-enxertos, com $10 \mathrm{~g} \mathrm{~L}^{-1}$ para ambos os portaenxertos e $90 \mathrm{~g} \mathrm{~L}^{-1}$ de sacarose para o porta-enxerto 'Taiwan Mamenashi' e 47,78g L ${ }^{-1}$ para 'Taiwan NashiC’ e pH 5,8; 3) valores de $\mathrm{pH}(4,0 ; 4,5 ; 5,0 ; 5,5 ; 6,0$ e 6,5) $\mathrm{x}$ porta-enxertos, sendo o meio de cultura constituído de $10 \mathrm{~g} \mathrm{~L}^{-1}$ de agar combinado com $90 \mathrm{~g} \mathrm{~L}^{-1}$ de sacarose para o porta-enxerto 'Taiwan Mamenashi’ e 47,78g L'-1 para ‘Taiwan Nashi-C’ e 795mg L-1 de ácido bórico; 4) temperaturas $(20 ; 25 ; 30$ e 35$)$ x porta-enxertos, sendo o meio de cultura constituído de $10 \mathrm{~g} \mathrm{~L}^{-1}$ de agar combinado com $90 \mathrm{~g} \mathrm{~L}^{-1}$ de sacarose para o porta-enxerto 'Taiwan Mamenashi' e 47,78g L'-1 para ‘Taiwan NashiC' e 795 mg L ${ }^{-1}$ de ácido bórico e pH 5,8; e 5) tempo de emissão do tubo polínico (1, 2, 3, 4, 5, 6 e 12 horas após a inoculação) x porta-enxertos, utilizando o meio de cultura constituído pelos melhores resultados dos experimentos anteriores. Os experimentos foram instalados de forma sequencial, sempre utilizando, no experimento posterior, o melhor resultado do anterior.

As culturas foram mantidas a $27^{\circ} \mathrm{C}$ e fotoperíodo de 24 horas, com exceção para o experimento de diferentes temperaturas. Com auxílio de lupa binocular com objetiva de 10 vezes, avaliou-se a porcentagem de grãos de pólen germinados após 24 horas de incubação, com exceção do experimento cinco (tempo de emissão do tubo polínico), que foi avaliado em intervalos pré-estabelecidos. Foram considerados germinados os grãos de pólen cujo comprimento do tubo polínico tivesse o dobro do próprio diâmetro.

Em todos os experimentos, o delineamento experimental utilizado foi inteiramente casualizado e com quatro repetições, sendo cada repetição constituída por uma placa de Petri em que foram contados aproximadamente 150 grãos de pólen em cada placa. Os dados foram submetidos à análise de variância, e as médias foram submetidas à regressão linear ou quadrática, em nível de $5 \%$ de probabilidade. As análises foram realizadas pelo Programa Computacional Sistema para Análise de Variância - SISVAR.

\section{RESULTADOS E DISCUSSÃO}

Para a utilização de agar e sacarose, verificouse que não houve interação entre os fatores testados para ambas os cultivares. Para o porta-enxerto 'Taiwan Mamenashi', houve um aumento linear na porcentagem de germinação dos grãos de pólen à medida que se elevou a concentração de agar (Figura 1A) e sacarose 

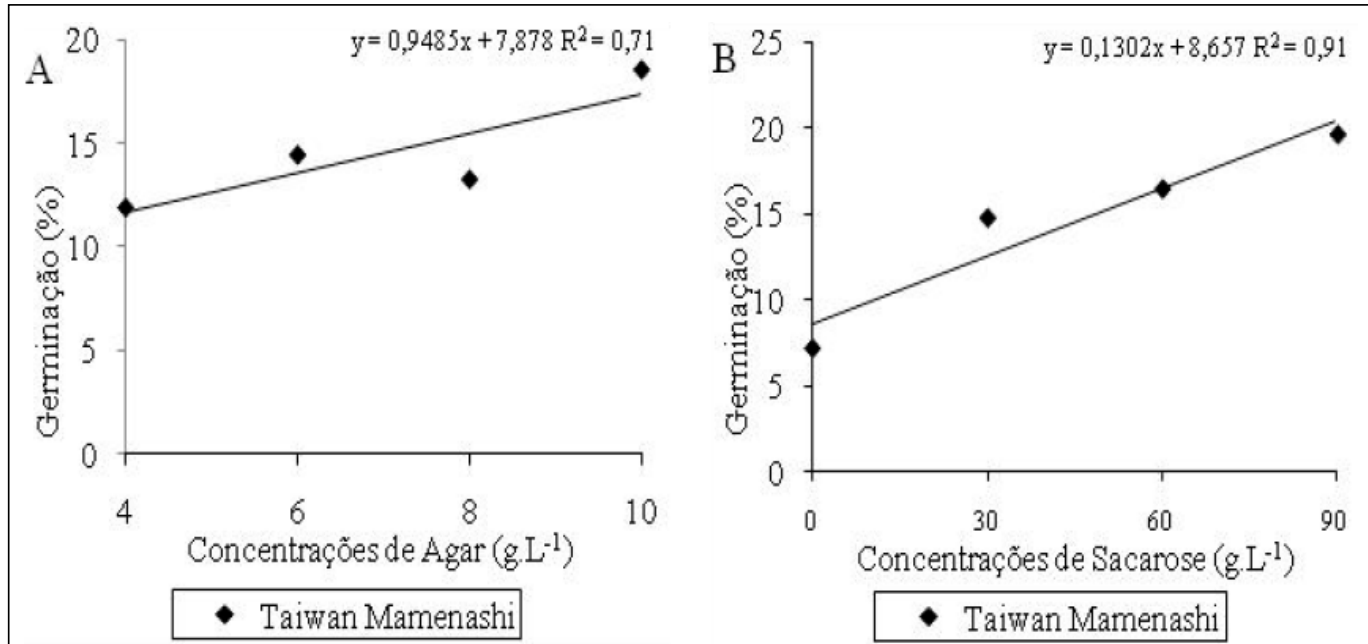

Figura 1 - Porcentagem de grãos de pólen germinados in vitro do porta-enxerto 'Taiwan Mamenashi' quando submetidos a diferentes concentrações de agar (1A) e sacarose (1B), avaliando-se quatro repetições de 150 pólen cada. Centro APTA Frutas/IAC, Jundiaí, SP, 2008.

(Figura 1B) no meio de cultura. Provavelmente a maior concentração de agar proporcionou uma superfície mais consistente do meio de cultura e um equilíbrio do potencial osmótico, o que facilitou a difusão dos nutrientes para os grãos de pólen e, consequentemente, maior porcentagem de germinação. ROMBERGER \& TABOR (1971) citam que o equilíbrio osmótico é importante para o cultivo in vitro.

Com relação à sacarose, a sua adição como fonte de carboidratos visa a suprir as necessidades metabólicas dos explantes, participando na geração de energia ou como fonte de esqueletos carbônicos para os processos biossintéticos implicados na diferenciação celular. Maior porcentagem de germinação com a elevação da concentração de sacarose pode ser explicada pela maior disponibilidade de energia na forma de carboidrato. Resultados semelhantes foram obtidos por XIE et al. (2004) no ajuste de diferentes componentes do meio de cultura, que observaram um acréscimo na porcentagem de germinação de grãos e pólen de peras asiáticas com o aumento da concentração de sacarose. O efeito da adição de sacarose na germinação de grãos de pólen deve estar relacionado ao equilíbrio osmótico da solução, além do maior fornecimento de energia necessária para o crescimento do tubo polínico.

Efeitos semelhantes são observados na germinação dos grãos de pólen do 'Taiwan Nashi-C' quando submetidos a diferentes concentrações de agar (Figura 2A). Em contrapartida, quando submetidos a

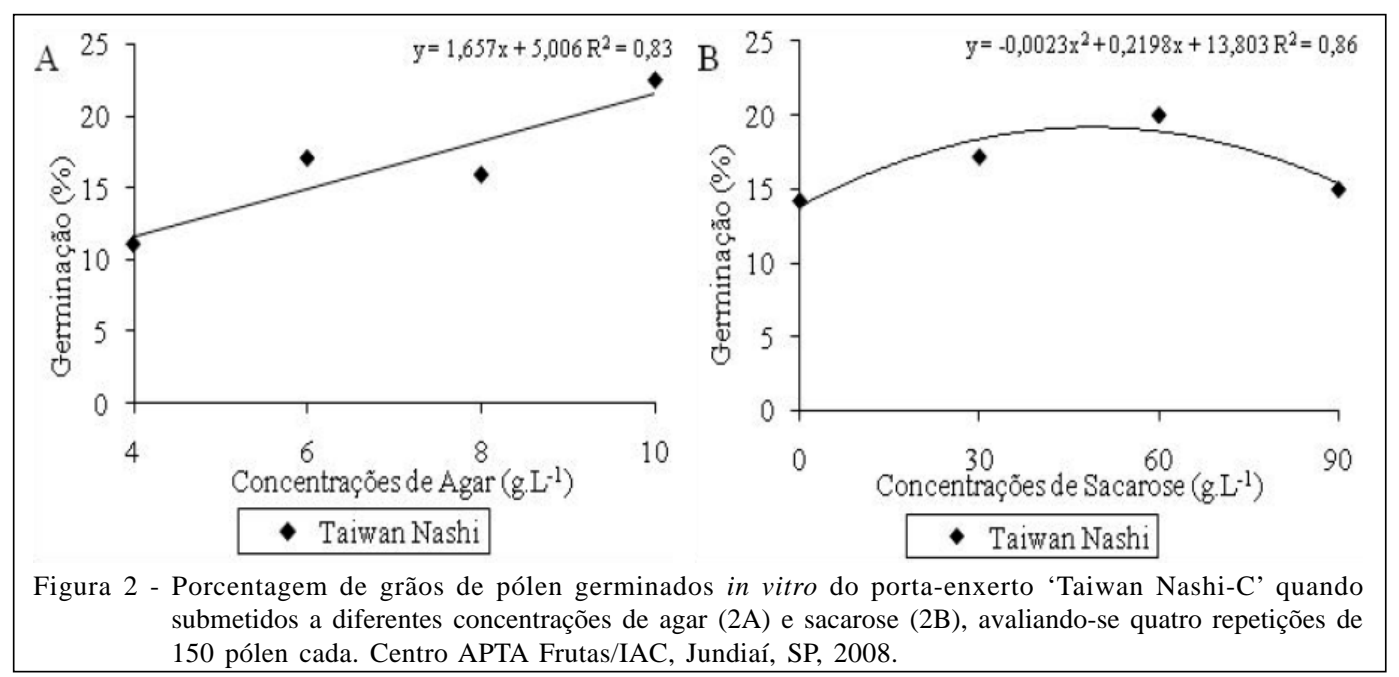

Ciência Rural, v.40, n.2, fev, 2010. 
diferentes concentrações de sacarose, verificou-se um incremento do porcentual de germinação de até 47,78g $\mathrm{L}^{-1}$ de sacarose, decrescendo em seguida (Figura 2B). Possivelmente essa diferença de concentração pode ser explicada por se tratar de genótipos diferentes.

Com relação ao nitrato de cálcio e ácido bórico, houve efeito significativo da interação entre os fatores testados para ambas as cultivares. Observouse que, tanto para 'Taiwan Mamenashi' (Figura 3A), quanto para 'Taiwan Nashi-C' (Figura 3B), os melhores resultados para a porcentagem de grãos de pólen germinados foram obtidos quando utilizados 795 e 838mg L $\mathrm{m}^{-1}$ de ácido bórico, na ausência de nitrato de cálcio. O boro na presença de sacarose forma o complexo ionizável sacarose-borato, o qual, segundo ASKIN et al. (1990), reage mais rapidamente com as membranas celulares, facilitando o desenvolvimento in vitro. É provável que, em função desse complexo, a adição de boro foi benéfica na germinação dos grãos de pólen dos porta-enxertos testados.

A adição de nitrato de cálcio não foi essencial para a germinação de in vitro de grãos de pólen. Entretanto, verificou-se a essencialidade do ácido bórico. Segundo GALLETA(1983), os polens de algumas espécies precisam de uma fonte de carbono, de boro e, frequentemente, de outros nutrientes para promover a sua germinação. Assim, no presente trabalho, constatou-se a essencialidade de uma fonte de boro para promover otimização da germinação dos grãos de pólen. Esse resultado também corrobora os trabalhos que constataram a necessidade de adição de uma fonte de boro para o sucesso na germinação de grãos de pólen de pereira (XIE et al., 2004; ZHANG et al., 2005).

Observa-se que o ajuste ideal de $\mathrm{pH}$ do meio de cultura situou-se entre 5,2 e 5,8 para as duas cultivares testadas (Figura 4). Para o 'Taiwan Mamenashi', houve um aumento na porcentagem de germinação de grãos de pólen até o valor máximo de pH 5,2. Nesse ajuste, germinaram 54,71\% dos grãos de pólen. Já para o ‘Taiwan Nashi-C’, o valor ideal do $\mathrm{pH}$ foi de 5,8, proporcionando um percentual de geminação de 42,8\%. Tais resultados estão de acordo com RAMOS et al (2008), o quais observaram que a melhor taxa de germinação de grãos de pólen de citros ocorre com $\mathrm{pH}$ entre 5,0 e 6,5.

Com relação à temperatura, verificou-se que esta influenciou significativamente a germinação de grãos de pólen em ambas as cultivares. Tanto para o 'Taiwan Mamenashi', quanto para o 'Taiwan Nashi-C', o aumento da temperatura favoreceu a germinação dos grãos de pólen até o valor próximo de $28^{\circ} \mathrm{C}$. A partir dessa temperatura, observa-se um decréscimo na porcentagem de polens germinados (Figura 5). VASILAKAKIS \& PORLINGS (1985), estudando a temperatura para germinação de grãos de pólen de pera, constataram que a taxa de crescimento do tubo polínico in vitro aumentou com a temperatura entre 15 e $25^{\circ} \mathrm{C}$.

Quanto ao tempo de emissão do tubo polínico, de modo geral, verifica-se, para ambos as cultivares, que a germinação teve início uma hora após a inoculação (Figura 6). Esses dados estão de acordo
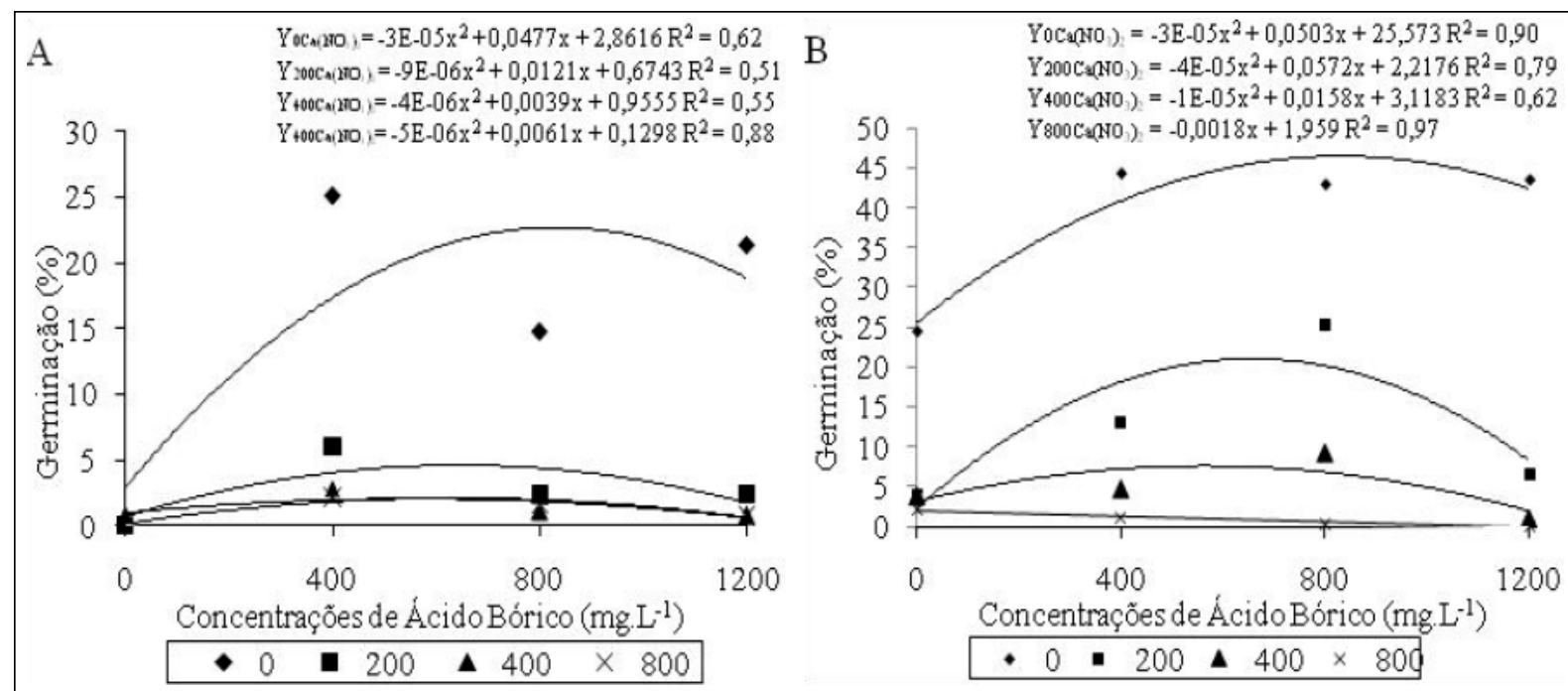

Figura 3 - Porcentagem de germinação in vitro de grãos de pólen de porta-enxertos de pereira 'Taiwan Mamenashi’ (3A) e 'Taiwan Nashi-C’ (3B) quando submetidos a diferentes concentrações de nitrato de cálcio e ácido bórico, avaliando-se quatro repetições de 150 pólen cada. Centro APTA Frutas/IAC, Jundiaí, SP, 2008.

Ciência Rural, v.40, n.2, fev, 2010. 


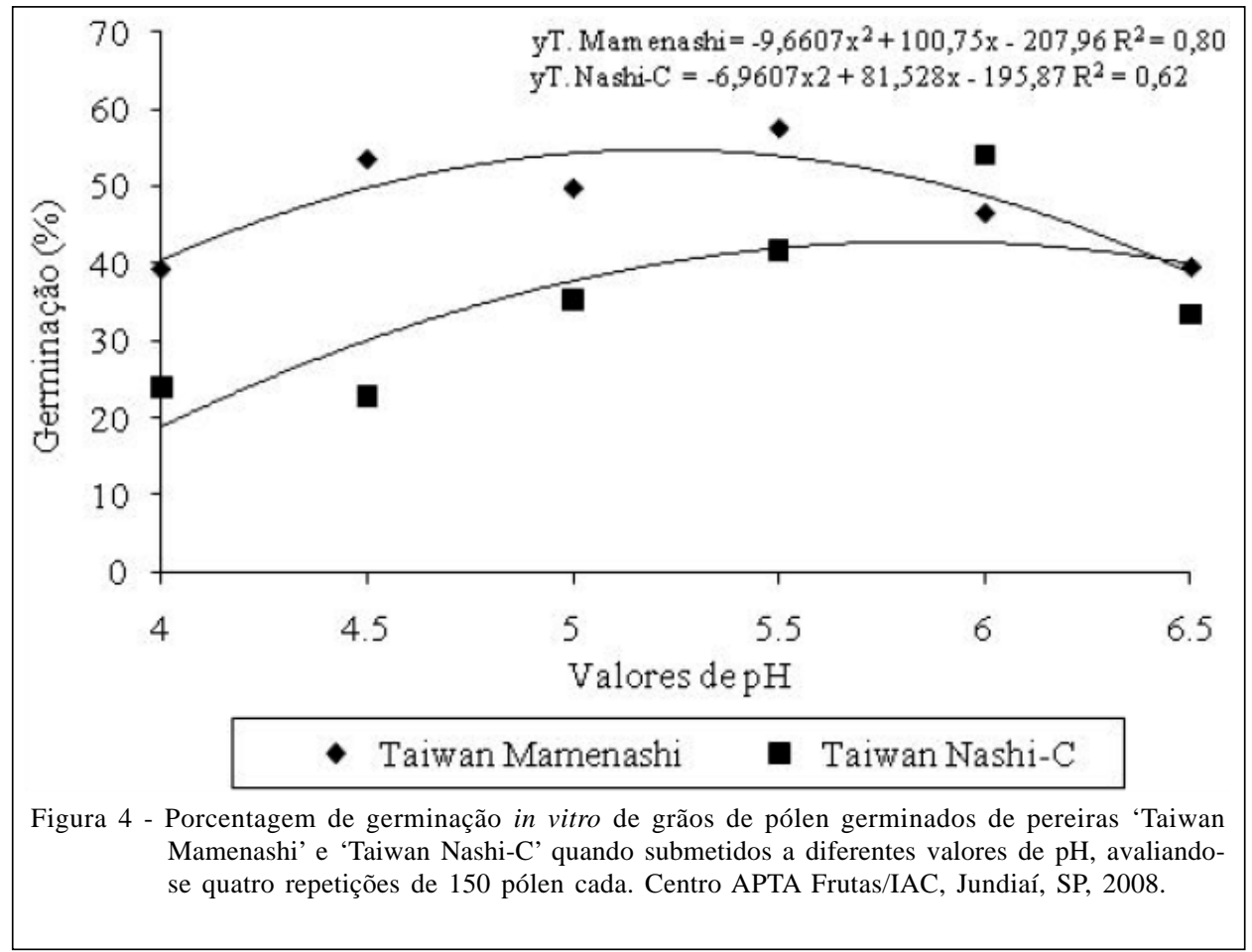

com KWACK \& BREWBAKER (1963), quando observaram que o início da emissão do tubo polínico em várias espécies é, na maioria das vezes, muito rápido.

Para o ‘Taiwan Mamenashi’, houve aumento linear na porcentagem de grãos de pólen que emitiram tubo polínico até as 12 horas de avaliação. Entretanto, para o 'Taiwan Nashi-C', a porcentagem máxima de germinação $(41,2 \%)$ foi obtida após 8 horas e 45 minutos. Em seguida, houve uma estabilização na porcentagem de grãos de pólen germinados (Figura 6).

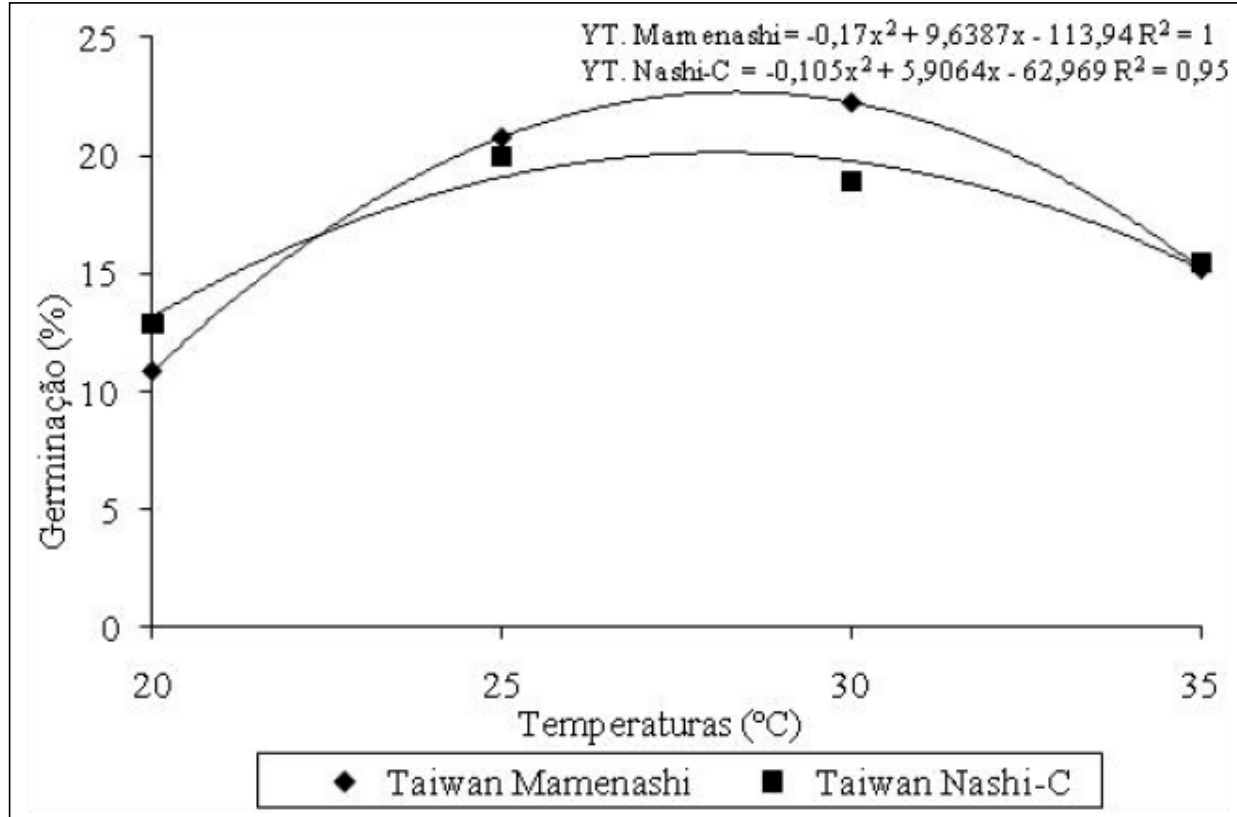

Figura 5 - Porcentagem de grãos de pólen germinados de porta-enxerto de pereira 'Taiwan Mamenashi' e 'Taiwan Nashi-C' quando submetidos a diferentes temperaturas, avaliando-se quatro repetições de 150 pólen cada. Centro APTA Frutas/IAC, Jundiaí, SP, 2008. 


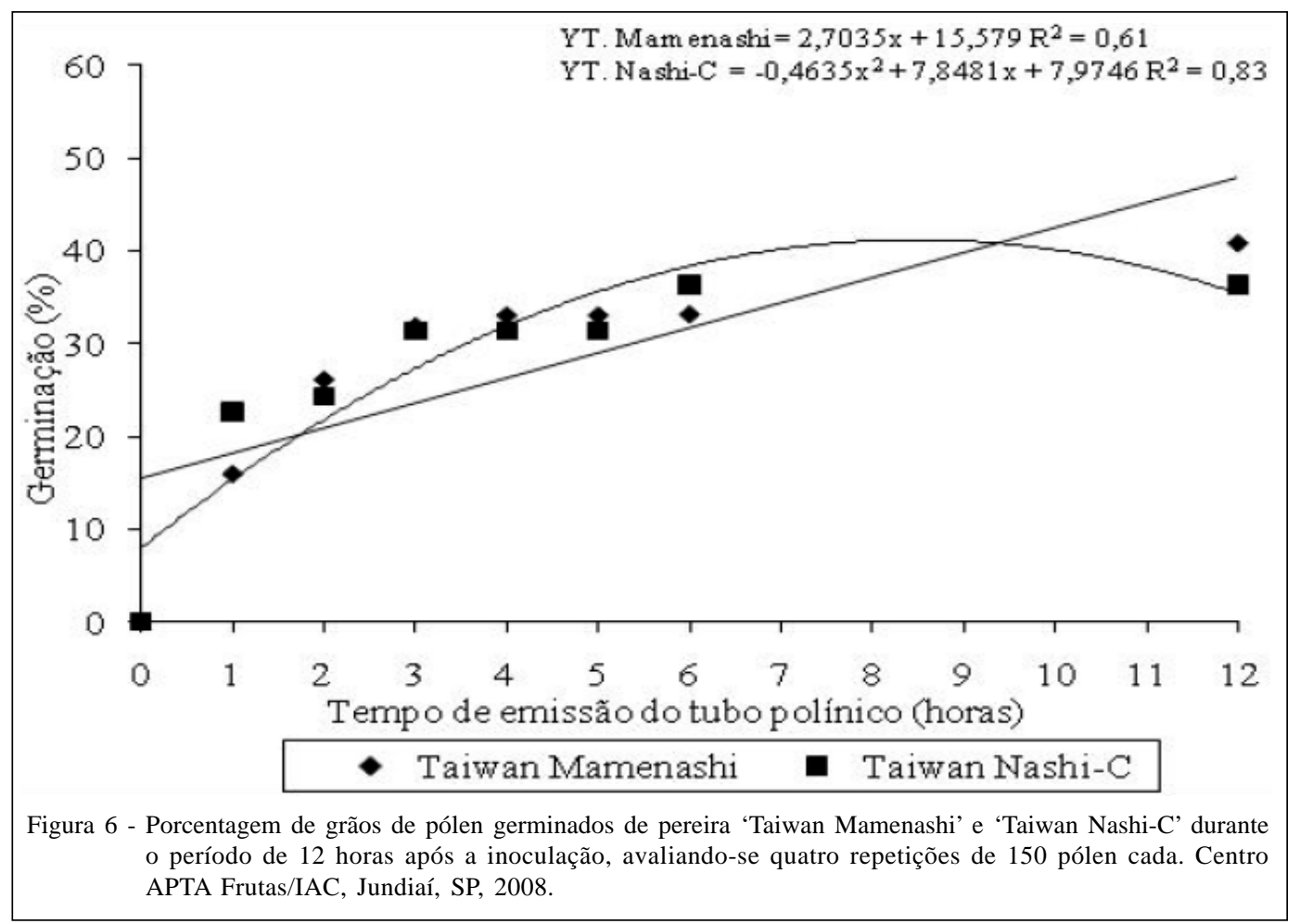

\section{CONCLUSÕES}

A utilização de $10 \mathrm{~g} \mathrm{~L}^{-1}$ de agar e $90 \mathrm{~g} \mathrm{~L}^{-1}$ de sacarose para o porta-enxerto 'Taiwan Mamenashi' e 47,78g L-1 para 'Taiwan Nashi-C', com 795 a 838 $\mathrm{mg} \mathrm{L}^{-1}$ de ácido bórico, na ausência de nitrato de cálcio, $\mathrm{pH}$ entre 5,2 e 5,8 e temperatura de $28^{\circ} \mathrm{C}$, proporcionou as melhores condições de germinação de grãos de grãos. A porcentagem máxima de polens germinados é obtida com oito horas após a inoculação para 'Taiwan NashiC' e com 12 horas para 'Taiwan Mamenashi'. Houve um incremento de mais de $40 \%$ na germinação de grãos de pólen com o ajuste do protocolo.

\section{REFERÊNCIAS}

ASKIN, A. et al. Investigations on the effects of gibberellic acid and boric acid on the germination of some sweet cherry pollens. Ege Universite Zirat Fakultesi Dergise, Dergise, v.27, n.03, p.105-116, 1990.

BARBOSA, W. et al. Asian pear breeding for subtropical areas of Brazil. Fruits, v.62, p.21-26, 2007. Disponível em: <http://www.fruitsjournal.org/index.php?option $=$ article\&access $=$ doi $\&$ doi $=10.1051 /$ fruits:2006045>. Acesso em: 17 jul. 2009. doi: 10.1051/fruits:2006045.

BARBOSA, W. et al. Formação rápida de mudas vigorosas de pêra com porta-enxerto oriental. O Agronômico, v.47, n.1, p.28-31, 1998.
BOLAT, Y.; PIRLAK, L. An investigation on pollen viability, germination and tube growth in some stone fruits. Tukish Journal of Agriculture Forestry, v.23, p.383-388, 1999.

GALLETA, G.J. Pollen and seed management. In: MOORE, J.N.; JANICK, J. Methods in fruits breeding. Indiana: Purdue University, 1983. p.23-47.

KWACK, B.H.; BREWBAKER, J.L. The essential role of calcium ion pollen germination and pollen tube growth. American Journal Botany, v.50, p.859-865, 1963.

RAMOS, J.D. et al. Receptividade do estigma e ajuste de protocolo para germinacão in vitro de grãos de pólen de citros. Interciência, v.33, n.1, p.51-55, 2008. Disponível em: <http:/ /www.scielo.org.ve/scielo.php?script=sci_arttext\&pid=S0378$18442008000100011 \& \operatorname{lng}=$ pt\&nrm=iso\&tlng $=\mathrm{pt}>$. Acesso em: 17 jul. 2009.

ROMBERger, J.A.; TABOR, C.A. The Picea abix shoot apical meristem in culture. American Journal of Botany, v.58, p.131-140, 1971.

VASILAKAKIS, M.; PORLING, I.C. Effect of temperature on pollen germination, pollen tube growth, effective pollination period, and fruit set of pear. Hort Science, v.20, n.4, p733735, 1985.

XIE, S. et al. Pollen viability of Asian pear and effect of PGR, $\mathrm{B}$ and sucrose on germination and pollen tube development. Journal of Fruit Science, v.21, n.4, p.289-294, 2004.

ZHANG, S.L. et al. Effects of medium components and $\mathrm{pH}$ on pollen germination and tube growth in pear (Pyrus pyrifolia). Xibei Zhiwu Xuebao, v.25, n.2, p.225-230, 2005. 